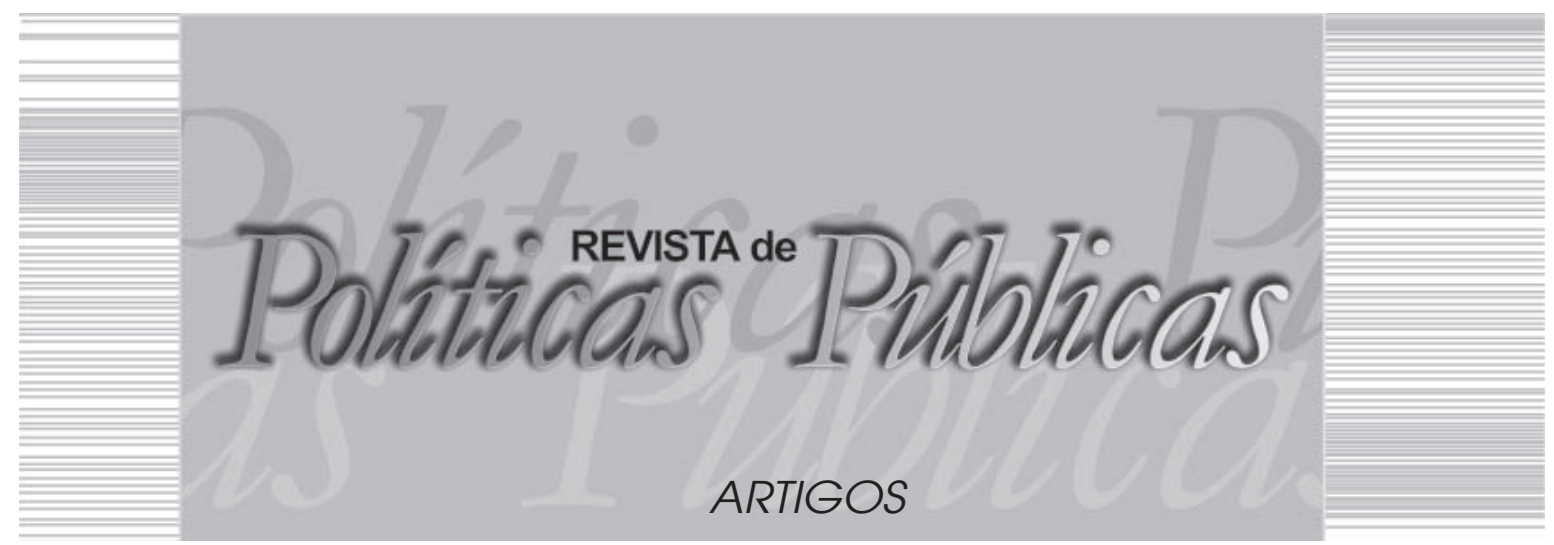

\title{
A ARISTOCRACIA OPERÁRIA E A PREVIDÊNCIA COMPLEMENTAR
}

\author{
Artur Bispo dos Santos Neto \\ Universidade Federal de Alagoas (UFAL) \\ Glaucya Núbia Barros dos Santos ${ }^{2}$ \\ Universidade Federal de Alagoas (UFAL)
}

\section{Resumo}

Este artigo enfatiza o processo de constituição da aristocracia operária na Inglaterra e sua formação no desenvolvimento do tardio capitalismo brasileiro, denotando o desempenho essencial dessa fração da classe operária para subordinar o conjunto da classe trabalhadora aos propósitos do capital. Mostra que a aristocracia operária desloca o desiderato de enfrentamento do capital para posição de adequação e acomodação ao status quo pela mediação da apologia da contrarreforma da Previdência Social, em que os fundos de pensão comparecem como reflexo da inócua tentativa de humanização do capitalismo via governança corporativa, responsabilidade social, sustentabilidade socioambiental, fundos éticos e aposentadoria por capitalização. Conclui que, através da ideologia da inclusão social e da necessidade de redistribuição de renda, a aristocracia operária desempenha função elementar nas obras orquestradas pelos governos Lula e Dilma Rousseff.

Palavras-chave: Previdência complementar, fundos de pensão, classe operária.

\footnotetext{
Bacharel em Filosofia. Doutor em Letras e Linguística. Professor no Programa de PósGraduação em Serviço Social da Universidade Federal de Alagoas (UFAL). E-mail: arturbisponeto@gmail.com

2 Assistente Social pela Universidade Federal de Alagoas (UFAL). E-mail: glaucyanubia@ hotmail.com. Universidade Federal de Alagoas - UFAL. Av. Manoel Severino Barbosa, Arapiraca - AL. CEP 57309-005
} 


\title{
THE LABOR ARISTOCRACY AND THE COMPLEMENTARY SOCIAL SECURITY
}

\begin{abstract}
This article emphasizes the labor aristocracy process in England and its formation in the late Brazilian capitalism, denoting how this labor class fraction performs an essential role to subordinate the working class to the purposes of the Capital. It is noted how the labor aristocracy can shift the desideratum of the capital confrontation to an adequacy and accommodation position to the status quo through the mediation of the apology of counter-reformation of the social security, in which the pension funds appear as the reflex of the harmless try in humanizing the capitalism before the corporative governance, the social responsibility, the socioenvironmental sustainability, the ethical funds and the pre-fund retirement systems. Concludes that, through the ideology of social inclusion and the need of income redistribution, the labor aristocracy plays the elementary function in the orchestrated constructions by the governments of Lula and Dilma Rousseff.
\end{abstract}

Key words: Complementary social security, pension funds, working class.

\section{INTRODUÇÂO}

O processo de colaboração de classe intensifica-se com o desenvolvimento das relações essencialmente capitalistas propiciadas pela superação do capital mercantil pelo capital industrial e a passagem do capitalismo concorrencial para o capitalismo dos monopólios, em que a Revolução Industrial implica a subordinação real dos trabalhadores aos propósitos do capital.

A subordinação do trabalho ao capital passa a contar com mediações cada vez mais sofisticadas de controle, nas quais a persuasão irradia-se por todos os poros da sociabilidade capitalista e os mecanismos coercitivos exercem papel secundário no processo de regulamentação da produtividade. Essas formas sofisticadas de controle, em que o direito comparece como elemento imprescindível, não implica que o capital não recorra aos mecanismos coercitivos sempre que a classe trabalhadora ultrapasse a linha de atuação demarcada pelo capital. 


\section{A ARISTOCRACIA OPERÁRIA COMO FORÇA AUXILIAR DO CAPITAL}

O movimento ascendente do capitalismo exige a subordinação da classe operária de maneira cada vez mais expressiva; por isso o capitalista, enquanto personificação do capital, procura obliterar o antagonismo essencial que perpassa a relação entre capital e trabalho, a constituir formas mais elaboradas de controle e subordinação do proletariado. O capital inicia um processo sofisticado de cooptação de determinada fração do proletariado a partir do final do século XIX, fazendo algumas concessões e estabelecendo alguns privilégios.

Lenin chegou ao conceito de aristocracia pela mediação da compreensão do desenvolvimento histórico do capitalismo inglês, enquanto capitalismo mais desenvolvido da Europa. Não se trata de uma categoria que emana do intelecto de Lenin (Marx e Engels), mas do desenvolvimento imanente da economia mais desenvolvida da época, em que uma fração da classe operária, que começa a afastar-se do conjunto da classe, usufrui de melhores salários e melhores condições de vida. Essa fração da classe correspondia à fração da classe operária mais bem preparada e mais bem organizada na forma de sindicatos e associações (trade unions) existentes na Inglaterra. Lenin considerava que o fundamento do revisionismo e do reformismo do proletariado inglês estava localizado no imperialismo da Inglaterra, que permitia algumas concessões a sua classe operária pela mediação da expropriação dos trabalhadores em outras regiões do mundo. (HOBSBAWN, 2013).

Ainda segundo Lenin, o desenvolvimento desigual e combinado do capitalismo permitia a emergência de um proletariado essencialmente economicista e corporativista. A pauta economicista das lutas orquestradas pela diferentes categorias do proletariado leva à sua fragmentação, fazendo que algumas se destaquem perante outras devido à sua pauta egoísta e em cooperação com os capitalistas para assegurar seus propósitos. Como consequência, assinala Hobsbawn (2013, p. 2, grifo do autor), "[...] um tal movimento puramente 'economicista' leva a quebrar a unidade e consciência política do proletariado e a enfraquecer ou neutralizar o seu papel revolucionário." A aristocracia operária brota quando o capitalismo reúne condições para fazer "[...] concessões significativas ao proletariado, dentro do qual certas camadas conseguem, por meio da sua 
especial escassez, engenho, posição estratégica, força organizacional etc., estabelecer muito melhores condições para si em detrimento das restantes." (HOBSBAWN, 2013, p. 2).

O crescimento do capital na época do imperialismo possibilita que os capitalistas repartam uma fração do excedente apropriado com uma elite dos trabalhadores, na perspectiva de estabelecer uma aliança de interesses contra os trabalhadores em geral. É uma espécie de aliança dos trabalhadores de um país contra os trabalhadores de outros países e de seus próprios países, em que uma fração da classe é claramente subornada para jogar no time da burguesia.

Hobsbawn (2013) salienta que uma fração da aristocracia operária acaba por se constituir como uma camada superior e se aburguesa. Esse fenômeno reverbera em todas as potências imperialistas e caracteriza a natureza dos principais partidos socialistas que integram a Segunda Internacional. No entanto, ao mesmo tempo que o imperialismo generaliza as condições para o surgimento de uma aristocracia operária, ele "[...] também produz as condições para o seu desaparecimento." (HOBSBAWN, 2013, p. 2).

A análise de Lenin serve, segundo Hobsbawn (2013), para justificar por que os partidos integrantes da Segunda Internacional acabaram por se converter em partidos da ordem burguesa e em agentes profissionais da administração do capital. Essa fração corrompida do proletariado é plenamente integrada aos propósitos da burguesia e amoldada ao processo de reprodução do sistema do capital; ela não pretende, em sã consciência, renunciar aos interesses do capital, porque está muito bem amoldada ao sistema instituído, como assinala Hobsbawn (2013, p. 3, grifo do autor):

[...] 'regressar' ao proletariado revolucionário, embora pudessem 'jurar em nome de Marx', onde o marxismo fosse popular entre os trabalhadores. Assim, os revolucionários devem rejeitar uma unidade fictícia entre o proletariado revolucionário e a fração filistina oportunista dentro do movimento dos trabalhadores.

Nota-se que a gênese da aristocracia operária brasileira está relacionada especialmente ao advento do parque industrial, ao estabelecimento das multinacionais no Brasil e à necessidade de criar mecanismos de controle do capital sobre o trabalho. O caráter colonial e hipertardio do capitalismo brasileiro permite observar a presença duma aristocracia operária semelhante àquela que se desenvolveu nas economias capitalistas mais desenvolvidas do globo somente no período histórico de declínio do regime empresarial-militar de 
1964 e no processo de reconfiguração do regime democrático no Brasil na década de 1980. (LESSA, 2014).

O surgimento da aristocracia operária no Brasil se inscreve num tempo histórico em que o capital apresenta sintomas de crise profunda em seu processo de expansão e acumulação. Enquanto no mundo inteiro se observa a adoção de medidas draconianas contra os trabalhadores, nota-se que o capital sente necessidade de fazer concessões a uma fração da classe operária brasileira para conter a ascendência do operariado e a resistência ao processo de flexibilização e desregulamentação das relações de trabalho na década de 1990.

A adesão das centrais sindicais, no decorrer da década de 1990, ao movimento de administração sindical pode ser constatada na constituição das câmaras setoriais, na apologia do sistema tripartite, na formulação dos conselhos das empresas estatais e de capital misto. Esse processo evolui para a formulação dos fundos de pensão como forma exemplar para assegurar a participação da aristocracia sindical na gestão das empresas estatais e no processo de privatização efetivado a partir do Governo Collor.

As contrarreformas da Previdência Social, orquestradas pelos governos Fernando Henrique Cardoso (FHC) e Lula, estavam plenamente amoldadas ao processo de privatização das estatais e as políticas neoliberais que foram instituídas em todo o mundo naquele ciclo histórico. O processo de desmonte da seguridade social está diretamente articulado à privatização; a contrarreforma da Previdência Social é seguida pelo fortalecimento dos sistemas de Previdência complementar e estes fundos exercerão um papel exemplar nos leilões privatizantes dos aeroportos, das rodovias, das empresas públicas e na constituição de empresas prestadoras de serviços para a Petrobras etc. Vejamos isso mais detalhadamente.

\section{A PRIVATIZAÇÃO DA PREVIDÊNCIA PÚBLICA E OS FUNDOS DE PENSÃO}

A história da Previdência Social está relacionada à gênese do proletariado brasileiro no começo do século XX, quando os operários constituíram uma rede própria de proteção para enfrentar as adversidades orquestradas pelo sistema do capital. Os sindicatos e associações anarcossindicalistas criaram as sociedades de ajuda mútua para enfrentar os momentos das colisões e greves operárias, bem como as situações de enfermidade e abandono dos trabalhado- 
res pelos patrões. As caixas ou sociedades mutualistas eram constituídas segundo os preceitos autogestionários e serviam como mecanismo para fortalecer a unidade dos trabalhadores ativos com os trabalhadores inativos. A base desses fundos de ajuda mútua era a solidariedade de classe e a necessidade de constituição de uma nova sociabilidade.

Os capitalistas conseguiram quebrar a unidade da classe operária pela mediação de medidas repressivas contra o movimento anarcossindical e pela constituição de medidas persuasivas, em que os fundos de ajuda mútua foram transformados na previdência pública. Esse processo foi marcado por conflitos e tensões tanto na Europa quanto no Brasil. Escreve Manzano (2012, p. 1):

Claro que os trabalhadores não entregariam seus recursos ao Es-
tado sem qualquer reação, portanto, houve um processo de coop-
tação, política e administrativa, para que as caixas de previdência
se tornassem públicas e sob a administração do Estado. O acordo
envolvia a contribuição patronal e do Estado (em vários países)
e a administração tripartite. Ou seja, os trabalhadores aceitaram
transferir seus fundos para a administração do Estado desde que
os patrões também contribuíssem e que seus sindicatos tivessem
participação na administração do uso desses recursos. Formou-se
assim a maior parte dos sistemas previdenciários.

Através do controle do Estado, o sistema de Previdência Social foi instituído no Brasil tendo como princípio a filosofia de que os trabalhadores dos tempos hodiernos financiam os trabalhadores das gerações passadas e que os trabalhadores das futuras gerações financiam os trabalhadores da atualidade. Assim como os trabalhadores do presente financiariam seus pais e avós, eles seriam financiados pelos seus filhos e netos. Um sistema que tinha como preceito a ajuda mútua das gerações. Além dos próprios trabalhadores, os empregadores entrariam com uma parte, o que significaria uma redução da taxa de mais-valia apropriada pelo capitalista.

A crise estrutural do sistema do capital no começo da década de 1970 impôs a necessidade de atacar os direitos sociais alcançados pelos trabalhadores. Nesse contexto apresenta-se a necessidade da contrarreforma da Previdência Social e a constituição dos fundos de pensão. Para isso, será fundamental afirmar o caráter deficitário da previdência social e a necessidade de constituição da previdência complementar. 
Na verdade, a previdência pública brasileira nunca foi deficitária. O problema é que os governos do Partido da Social Democracia Brasileira (PSDB) ${ }^{1}$ e do Partido dos Trabalhadores (PT) ${ }^{2}$ adotaram o discurso do déficit da previdência pública e sua desarticulação da Seguridade Social. O desrespeito ao dispositivo constitucional acontece através da Desvinculação das Receitas da União (DRU), em que os recursos da Seguridade Social (previdência pública) são desviados para assegurar o superávit primário e o pagamento da dívida pública.

O fortalecimento dos fundos de pensão representa um duro golpe na previdência social e na entronização da previdência privada para atender às demandas do mercado, e não aos trabalhadores. Os fundos de pensão estão fundamentados na lógica do individualismo possessivo, no empreendedorismo, na apologia do sistema financeiro, e não na solidariedade dos trabalhadores entre si.

Embora possamos encontrar vestígios dos fundos de pensão em épocas remotas, eles foram regulamentados pela primeira vez na época da ditadura militar-empresarial (Lei ${ }^{\circ} 6.435$, de 15 de julho de 1977), e reconfigurados através das Leis Complementares $\mathrm{n}^{\circ} 108$ e $\mathrm{n}^{\circ} 109$, de 29 de maio de $2001^{3}$. A alteração da natureza dos fundos de pensão no começo do século XXI contou com a participação ativa de setores da aristocracia sindical como Luiz Gushiken ${ }^{4}$ (ex-presidente do Sindicato dos Bancários de São Paulo), Ricardo Berzoini (ex-presidente do Sindicato dos Bancários São Paulo, Osasco e região), José Pimentel (Diretor do Sindicato dos Bancários do Ceará e Secretário-Geral da Central Única dos Trabalhadores [CUT]), Sérgio Rosa, João Vaccari etc. O interesse da aristocracia sindical pelos fundos de pensão cresceu na época da privatização iniciada pelo governo Collor de Mello, quando Luiz Gushiken e seus asseclas passaram a fazer a apologia aberta à sua adesão no interior da CUT e do PT.

O processo de formação dos sindicalistas na administração dos fundos de pensão passou a ser veiculado numa cartilha elaborada pela aristocracia sindical concentrada no setor bancário no começo da década de 1990 e evoluiu para eletricitários, telefônicos, petroleiros e alguns segmentos dos metalúrgicos. Nesse contexto, as principais Centrais Sindicais do país (CUT, Confederação Geral dos Trabalhadores [CGT] e Força Sindical) "[...] passaram a reivindicar a criação de previdência privada para seus associados e, sobretudo, 
a exigir a participação ativa dos trabalhadores nos conselhos dos fundos." (JARDIM, 2008, p. 1).

Além de exercer papel importante no comando da contrarreforma da Previdência Social de 2003, a aristocracia sindical teve função exemplar na elaboração da Carta de Brasília (2000), que reivindicava a ampliação do segmento de Previdência complementar no país. Para a aristocracia sindical, os fundos de pensão são duplamente positivos para os trabalhadores, pois tanto asseguram uma renda maior na previdência quanto possibilitam o fortalecimento da poupança interna e asseguram investimentos que geram emprego e renda. A participação da aristocracia operária na administração dos fundos foi postulada como a forma para acabar com a malversação dos recursos e assegurar transparência no gerenciamento dos recursos contraídos. (JARDIM, 2010).

Os fundos tiveram participação ativa no processo de privatização das empresas estatais na época de FHC, como no processo de privatização da Companhia Vale do Rio Doce e das Companhias Telefônicas. Os fundos de pensão encontraram sua plena aplicabilidade no governo Lula. De acordo com Jardim (2010, p. 24), o fundo de pensão brasileiro foi constituído segundo o modelo francês, mediante intenso diálogo estabelecido "[...] entre a CUT e a CFDT francesa, quando da implantação do dispositivo no Brasil, em 2003."

Com a chegada de Luiz Inácio Lula da Silva ao poder, em 2003, a aristocracia sindical assumiu 11 dos 33 ministérios e partilhou a direção da Petrobras, Banco do Brasil, Caixa e Correios com os aliados do Partido do Movimento Democrático Brasileiro (PMDB) e Partido Trabalhista Brasileiro (PTB). Ricardo Berzoini foi para o Ministério da Previdência e Luiz Gushiken ficou com o Ministério da Comunicação e Gestão Estratégica; Sérgio Rosa assumiu o controle da Previ, Guilherme Lacerda, a Funcef, e Wagner Pinheiro, a Petros. O ministro chefe da secretaria-geral do Governo Lula, ex-dirigente do Sindicato dos Professores da Rede Estadual de Minas Gerais, Luiz Dulci, insistiu na necessidade de que as centrais apoiassem a contrarreforma da previdência e a constituição dos fundos de pensão. Afirma Dulci (apud SILVEIRA, 2003, p. 2): "Se as centrais sindicais querem contribuir para que um país como o Brasil se desenvolva - gerando emprego, renda e fazendo inclusão social -, uma das maneiras pode ser esta: influenciar os Fundos de Pensão dos quais fazem parte a investir mais no Brasil." 
Em 2010, os fundos de pensão brasileiros movimentavam um montante de 504 bilhões, o equivalente a $17,5 \%$ do Produto Interno Brasileiro (PIB) nacional, num mercado formado por 369 entidades, das quais $64,7 \%$ eram fundos de patrocínio público e $35,3 \%$ eram de procedência privada. (JARDIM, 2010). Segundo Jardim (2010, p. 25, grifo do autor):

\begin{abstract}
É na direção/gestão desses fundos que se encontram alguns sindicalistas oriundos do setor bancário e petroleiro, os quais influenciam sobremaneira as carteiras de investimentos dos fundos, consolidando novas formas de investimento com critérios de sustentabilidade e reforçando desenhos institucionais, como os Fundos de Investimentos em Participações (FIPs), que são direcionados para a construção de uma possível "economia social".
\end{abstract}

A aristocracia operária brasileira encontrou na administração dos fundos de pensão um espaço significativo para demonstrar a possibilidade de oferecer uma face humana ao capital. A tentativa de humanizar o capitalismo manifesta-se na tentativa de constituição de uma economia social ou de uma economia solidária, enquanto mediação do modo petista de governar. O discurso centrado na possibilidade de equalizar as desigualdades sociais existentes no país e na geração de emprego e renda oblitera a verdadeira essencialidade dos fundos de pensão, ou seja, que esses fundos tratam os trabalhadores segundo a lógica do capital, em que cada trabalhador é um investidor que ao final de sua vida "[...] poderá receber, em parcelas calculadas de acordo com sua expectativa de vida, os recursos de sua conta." (MANZANO, 2012, p. 1).

E enquanto uma pequena fração da classe trabalhadora se beneficia mediante a participação na gestão dos fundos de pensão, a grande maioria deve entregar uma parte de seu salário para assegurar uma aposentaria complementar ao final de sua vida, quando deveria estar utilizando a totalidade de seu salário para reproduzir a existência imediata enquanto trabalhador. No entanto, uma parte de seu salário é desviada da reprodução imediata para servir à reprodução do capital, ampliando a taxa de mais-valia capitalizada. Através dos fundos de pensão, os trabalhadores são duplamente explorados. Escreve Manzano (2012, p. 1): "Assim, os trabalhadores estão contribuindo ainda mais - além da mais-valia que produzem ao trabalhar - para a acumulação de capital, ao fornecerem um acúmulo de recursos para investimentos capitalistas." 
A superação da Previdência Social pelos fundos de pensão representa a subsunção dos trabalhadores aos propósitos do capital. Os fundos de pensão significam a conversão da velha solidariedade dos operários entre si para a solidariedade da classe operária ao capital financeiro e privatista. No entanto, os dirigentes do PT (José Genoíno, José Dirceu, Lula etc.) e a aristocracia sindical afirmavam que a contrarreforma da previdência e a constituição dos fundos de pensão tinham como mote a necessidade de os trabalhadores assegurarem garantias eficientes e pragmáticas às futuras gerações. O presidente da CUT, João Antônio Felício defendeu a contrarreforma da previdência de 2003 nos seguintes termos:

Porque, na proposta do governo, não significa privatização o fato de haver um teto de dez salários mínimos e a possibilidade de criação do fundo de pensão público sem fins lucrativos, fechado e com administração quadripartite. A CUT sempre foi contra o processo de privatização feito pelos governos anteriores. Portanto, seria um absurdo nos posicionarmos favoráveis à criação de fundos de pensão privados. Mas, francamente, não vemos isso na proposta do governo. (FELÍCIO apud JARDIM, 2010, p. 37).

A participação da aristocracia operária no processo de administração do capital pode ser observada na natureza dos fundos de pensão que foram constituídos de maneira mais precisa na época do Governo Lula. Escreve Jardim (2010, p. 17):

A preponderância dos fundos de pensão faz parte de um contexto de soberania das finanças e de seus subprodutos, tais como a governança corporativa, a responsabilidade social, a sustentabilidade socioambiental, os fundos éticos e a aposentadoria por capitalização. Além disso, ocasiona o surgimento de novos atores no mercado financeiro (sindicalistas, empresários éticos, trabalhadores acionistas, dirigentes de ONGs), o que acarreta, em certa medida, a recomposição das elites nacionais, especialmente no caso do Brasil.

Os fundos de pensão representam uma significativa regressão no conceito de seguridade social e previdência social, e um avanço na construção duma previdência (privada) plenamente subordinada aos propósitos do mercado, em que o sucesso do novo sistema privado de previdência passa pela mediação do sistema financeiro, do processo de capitalização e da conexão com os propósitos do mercado. Os fundos de pensão têm como propósito essencial operar a capitalização da mais-valia indiretamente apropriada do trabalhador, na qual os recursos captados fazem girar tanto o sistema especulativo quanto o teatro do sistema especulativo. Os ideólogos e executores 
dos fundos de pensão têm clareza da finalidade última dos fundos de pensão: servir ao processo de recomposição das elites nacionais. A finalidade central é transformar setores da aristocracia sindical em partícipes do teatro da grande burguesia nacional.

Para isso, o movimento sindical deve abandonar o terreno da luta por melhores salários, melhores condições de trabalho e redução da jornada de trabalho, para adentrar no universo da administração do capital sob a clivagem do discurso da moralidade, da pureza de princípios e da gestão responsável. A nova estratégia sindical tem como eixo a moralização do capital, a preocupação com a diminuição da desigualdade social e a afirmação dos preceitos de uma administração com responsabilidade social. É a tentativa inócua de reformar o capital. A necessidade de unir-se ao capital ao invés de contrapor-se a ele foi afirmada por Jair Meneguelli (apud SILVEIRA, 2003, p. 1) na apologia estabelecida aos lucros das empresas, em que afirma: "[...] o lucro é legítimo dentro do capitalismo."; e completou: "[...] sem ele, a empresa não se mantém, não investe, não gera empregos."

Jair Meneguelli (apud SILVEIRA, 2003, p. 1) e a aristocracia sindical assumiram integralmente o ditado popular que afirma: "Se você não pode com o inimigo, melhor se juntar a ele". O arrefecimento das greves operárias de enfrentamento do capital na década de 1990 é ditado pela necessidade de aliar-se ao capital. Nesse processo, os sindicatos e as centrais devem dialogar com o mercado financeiro e desenvolver uma posição favorável ao trabalho abstrato e alienado.

Essa é a configuração hegemônica do movimento sindical brasileiro desde a década de 1990. Um movimento que entende a si mesmo como reciclado e adaptado aos novos tempos. A aristocracia sindical deve desempenhar as funções de domadores do capital pela mediação do controle dos fundos de pensão e dos conselhos administrativos do Fundo de Amparo ao Trabalhador (FAT), do Fundo de Garantia por Tempo de Serviço (FGTS), da gestão do Estado e da administração do capital. Reconhecendo a impossibilidade do socialismo, a tarefa que cabe ao novo sindicalismo, representado pela CUT (Força Sindical, CGT, Confederação Brasileira dos Trabalhadores [CBT] e consortes), é modernizar-se e adaptar-se aos no- 
vos tempos mediante a inserção na lógica do mercado, ou seja, os sindicatos devem manter-se articulados às suas bases pela mediação do dinheiro e das possibilidades de uma aposentaria afortunada.

A ascendência dos petistas ao governo central representou o ponto culminante da política conciliatória da aristocracia operária sindical com o capital, em que os fundos de pensão são administrados segundo os propósitos do capital. É pela mediação do mercado que se tenta operar a agenda política da redistribuição de renda e inclusão social. Os fundos de pensão são parceiros tanto do capital especulativo quanto do capital produtivo. Anota Jardim (2010, p. 21): "Portanto, estimulados institucionalmente e cognitivamente durante o governo Lula, os fundos de pensão têm como prioridade o investimento em atividades produtivas, de forma a gerar emprego e renda, cujo destaque ocorre nos seguintes setores: infraestrutura, energia, transporte e meio ambiente."

$\mathrm{Na}$ tentativa de efetivar a proposta de redistribuição de renda no país, os fundos de pensão passaram a apoiar os projetos de infraestrutura, energia, transporte, agronegócio e meio ambiente nos governos de Lula e Dilma. Os fundos de pensão dos servidores das estatais são os principais agentes dos investimentos realizados pelo governo Lula (Minha Casa Minha Vida [PMCMV], Bolsa Família [BF] etc.). Ao participar dos conselhos das empresas como acionistas, os representantes dos trabalhadores (aristocracia operária) passaram a gerir essas empresas como uma nova personificação do capital. Na condição de proprietários-acionistas das empresas compradas no processo de privatização estatal ou como compradores das ações de determinadas empresas, os representantes dos fundos de pensão são gestores que têm de aplicar os preceitos inexoráveis do capital sobre o trabalho, em que o lucro não passa de um mecanismo de obliteração da mais-valia expropriada dos trabalhadores, com a anuência da própria classe expropriada. Assinala Jardim (2010, p. 66): "Pela lógica da governança corporativa, os fundos de pensão exercem poder disciplinador e de vigilância sobre as empresas, uma vez que são seus principais credores." Oliveira (2003, p. 148, grifo do autor) descreve a anatomia da aristocracia sindical:

Não se trata de equívoco nem da tomada de empréstimo do programa do PSDB, mas de uma verdadeira nova classe social, que 


\begin{abstract}
se estrutura sobre, de um lado, técnicos economistas doublés de banqueiros, núcleo duro do PSDB, e trabalhadores transformados em operadores de fundos de previdência, núcleo duro do PT. A identidade dos dois casos reside no controle do acesso aos fundos públicos, no conhecimento do "mapa da mina".
\end{abstract}

Os fundos de pensão são ainda credores ou agiotas do Estado, e se apresentam como entidades que financiam as atividades do Estado. Na condição de credores do Estado, os fundos são partícipes também da gestão do Estado. Desempenham funções de agentes da dívida pública e são favorecidos pelas elevadas taxas de juros cobradas pelas instituições financeiras ao Estado brasileiro.

Para legitimar a participação da burocracia sindical e da aristocracia na administração dos fundos de pensão e das empresas por estes partilhadas, há todo um discurso fundado na necessidade da transparência das contas, na responsabilidade social das instituições envolvidas e na possibilidade de minimizar as distorções sociais e as injustiças cometidas contra os mais pobres no Brasil. O discurso da responsabilidade social das empresas circunscreve-se à política de combate à discriminação de gênero, ao trabalho infantil e ao racismo. No entanto, a principal responsabilidade social dos fundos de pensão no Brasil, segundo o presidente da Petros, Wagner Pinheiro, é com os cotistas dos fundos de pensão. O interesse do trabalhador cotista está acima do trabalhador não cotista, pois os lucros dos fundos de pensão devem assegurar a responsabilidade com o pagamento das aposentarias de seus filiados. (JARDIM, 2010). Para assegurar isso, todos os mecanismos ensejados pelo capital são pertinentes. Nos EUA, por exemplo, os fundos de pensão investiram nas últimas décadas vultosos recursos financeiros na indústria armamentista e na indústria tabagista.

Vejamos mais detalhadamente o movimento patrimonial e financeiro dos dois principais fundos de pensão existentes no Brasil, enquanto mera expressão da constelação formada por mais de trezentos fundos. As primeiras posições são controladas pelos empreendimentos Caixa de Previdência dos Funcionários do Banco do Brasil (Previ - Banco do Brasil [BB]), Petros (Petrobras) e Fundação dos Economiários Federais (Funcef - Caixa). Destas empresas, somente a Caixa Econômica Federal (CEF) é uma empresa ainda plenamente estatal; as demais são de economia mista. Os fundos de pensão que seguem os três primeiros são: Funcesp, Fundação Itaú Unibanco, Valia, Sistel, Forluz, Real Grandeza, Banesprev, Funda- 
ção Atlântico, Fapes, Postalis, Fundação Copel, Centrus, Previdência Usiminas, Telos, HSBC Fundo de Pensão, Fachesf, Eletroceee, Visão Prev, Economus, Serpros, Ceres, CBS Previdência etc.

\section{- Previ}

A Previ, criada em 1904, constitui o maior fundo de pensão existente na América Latina e é o $24^{\circ}$ no ranking mundial. Possuía, em setembro de 2015, um patrimônio de 164 bilhões. A Previ desempenhou posição destacada no processo de privatização orquestrado pelos governos do PSDB e do PT, constituindo-se como importante acionista de empresas como Companhia Siderúrgica Nacional e Embraer. Conta com participação no sistema financeiro com ações no Banco do Brasil, Bradesco, Itaú Unibanco etc. e com significativa participação no complexo produtivo, com ações em empresas estatais e privadas como Tupy, Sauipe, Paranapanema, Vale, Embraer, CPFL Energia, Fiago, Fras-Le, Petrobras, Sete Brasil, Jereissati Telecom etc. Eis a listagem com percentuais de participação da Previ em cada empresa do complexo produtivo e do sistema financeiro.

Tabela 1 - Quadro geral com percentuais de participação da PREVI (30/06/2016)

\begin{tabular}{l|c|l|c}
\hline \multicolumn{4}{c}{ POSIÇÃO EM 30/09/2015 } \\
\hline \multicolumn{1}{c|}{ EmPresas } & PREVI & \multicolumn{1}{c}{ Empresas } & PREVI \\
\hline 521 PARTICIPAÇÕES & 100,00 & JEREISSATI PARTICIPAÇÕS & 18,42 \\
\hline AFLUENTE GERAÇÃO & 2,29 & JEREISSATI TELECOM & 19,78 \\
\hline AFLUENTE TRANSMISSÃO & 2,29 & KEPLER WEBER & 17,47 \\
\hline AMBEV & 2,49 & KLABIN & 0,11 \\
\hline BANCO DO BRASIL & 10,38 & MAGAZINE LUIZA & 1,76 \\
\hline BB SEGURIDADE & 0,67 & METALÚRGICA GERDAU S.A. & 1,61 \\
\hline BRADESCO & 1,44 & NEOENERGIA S.A. & 49,01 \\
\hline BRF - BRASIL FOODS S.A. & 10,03 & NEWTEL PART. & 22,53 \\
\hline COELBA & 2,29 & OI S.A. & 0,75 \\
\hline COSERN & 1,54 & PARANAPANEMA & 23,96 \\
\hline CPFL ENERGIA & 29,45 & PETROBRAS & 2,81 \\
\hline EMBRAER & 5,31 & RANDON & 6,80 \\
\hline FIAGO & 51,89 & RUMO LOGÍSTICA & 2,67 \\
\hline FIBRIA CELULOSE & 0,96 & SAUÍPE & 100,00 \\
\hline FORJAS TAURUS & 6,78 & SETE BRASIL & $2,30 *$ \\
\hline FRAS-LE & 22,50 & SUL 116 PARTICIPAÇÕES & 11,17 \\
\hline
\end{tabular}


A ARISTOCRACIA OPERÁRIA E A PREVIDÊNCIA COMPLEMENTAR

\begin{tabular}{l|c|l|c}
\hline GERDAU & 0,68 & SUZANO PAPEL E CELULOSE & 0,64 \\
\hline INVEPAR & 25,56 & TUPY & 26,70 \\
\hline INVITEL LEGACY & 19,99 & ULTRAPAR PARTICIPAÇÕES & 5,52 \\
\hline $\begin{array}{l}\text { ITAÚUNIBANCO HOLDING } \\
\text { S.A. }\end{array}$ & 1,59 & VALE & $15,61^{\text {** }}$ \\
\hline ITAUSA & 2,14 & WEG & 0,07 \\
\hline
\end{tabular}

Fonte: CAIXA DE PREVIDÊNCIA DOS FUNCIONÁRIOS DO BANCO DO BRASIL. Investimentos - Empresas participadas. Botafogo, 2015. Disponível em:<http://www.previ.com.br/investimentos/ empresas-participadas>. Acesso em: 30 set. 2015.

Notas: * Participação via Fundo de Investimentos em Participações Sondas - FIP Sondas. resgatáveis.

** Reflete a participação direta (Previ Futuro) e indireta (Plano 1), considerando ações

A Previ constituiu-se como modelo de administração dos fundos de pensão para a constelação de fundos instituídos no decorrer da década de 1990 e nos governos petistas, nos quais Luiz Gushiken exerceu função singular na sua efetivação. A Previ plasma-se como espaço para que a aristocracia sindical possa claramente assumir a condição modelar de personificação do capital sob a roupagem ideológica da cooperação de classe. Pela mediação dos fundos de pensão a aristocracia sindical participou das atividades fraudulentas que perpassaram as privatizações orquestradas pelos governos Collor, Itamar, FHC, Lula e Dilma, e estão todas envolvidas nas denúncias da Lava Jato. É bastante conhecida, por exemplo,

[...] a participação da Previ (fundo de pensão dos funcionários do Banco do Brasil), junto com o banco Opportunity, nas privatizações do sistema Telebras. Atualmente os diretores da Previ participam do conselho gestor que controla a empresa que reúne a Brasil Telecom, Tele Norte Leste, Telemig Celular e a Tele Norte Celular. (CRUZ, 2005).

Além disso, a atuação dos diretores deste fundo de pensão exerceu função basilar para quebrar a espinha dorsal do movimento sindical que apresentava resistência à contrarreforma da Previdência Social.

\section{- $\quad$ Funcef (Caixa)}

A Funcef foi criada em 15 de junho de 1977 e constitui o terceiro maior fundo de pensão do país, achando-se entre os maiores da América Latina. A Previdência complementar dos funcionários da CEF, conforme Tabela 2, conta com a participação de 136 mil funcionários e possuía, em 2014, um patrimônio ativo de mais de 54 
bilhões de reais. A Funcef procura colaborar no desenvolvimento do capitalismo nacional mediante investimentos em setores diversos, como imóveis, renda fixa, renda variável, investimentos estruturados e operações com participantes.

Tabela 2 - Mapa de investimentos realizados pelo Funcef em 2014

\begin{tabular}{|c|c|c|c|c|}
\hline \multicolumn{5}{|c|}{ Rentabilidade por segmento de aplicação - 2014} \\
\hline Segmentos & Saldo & Participação \% & Rent. Acum. 2014 & Referencial \\
\hline Renda Fixa & 25.550 .110 & $557,04 \%$ & $12,61 \%$ & $12,07 \%$ \\
\hline Renda Variável & 15.272 .429 & $332,97 \%$ & $-11,83 \%$ & $-2,91 \%$ \\
\hline Investimentos Estruturados & 5.881 .649 & $128,23 \%$ & $7,62 \%$ & $12,07 \%$ \\
\hline Investimentos Imobiliários & 5.222 .410 & $113,86 \%$ & $16,77 \%$ & $12,07 \%$ \\
\hline Operações com participantes & 2.334 .253 & $50,89 \%$ & $16,29 \%$ & $12,07 \%$ \\
\hline Outros Investimentos & 12.603 & $0,27 \%$ & $5,28 \%$ & $12,07 \%$ \\
\hline Total' & 54.274 .320 & $1183,29 \%$ & $4,44 \%$ & $12,07 \%$ \\
\hline
\end{tabular}

${ }_{1}^{1}$ Está incluso no total o valor de R\$ 866 mil referente ao Disponivel.

Fonte: FUNDAÇÃO DOS ECONOMIÁRIOS FEDERAIS. Principais números. Brasília, DF, 2014. Disponível em:<https://www.funcef.com.br/sobre-a-funcef/principais-numeros/>. Acesso em: 5 abr. 2016.

O relatório do quadro geral dos fundos de pensão apresentado pela Abrapp, em novembro de 2015, afirma que "[...] os ativos dos fundos de pensão atingiram R $\$ 729$ bilhões, equivalente a 12,5\% do PIB." (ASSOCIAÇÃO BRASILEIRA DAS ENTIDADES FECHADAS DE PREVIDÊNCIA PRIVADA, 2016, p. 1), com mais de 2,5 milhões de participantes ativos, 3,9 milhões dependentes e 736 mil pessoas assistidas. Houve momentos do cenário nacional em que os fundos de pensão alcançaram percentuais acima dos 17\% (2007) do PIB nacional. Essa foi a taxa mais baixa alcançada nos últimos dez anos (2005-2015), o que significa que os fundos sofreram perdas nos investimentos operacionalizados, especialmente na bolsa de valores e nos negócios realizados com as empresas envolvidas nas denúncias da Lava Jato, como Odebrecht, OAS, Queiroz Galvão etc. Mesmo assim, a sua participação na economia nacional é bastante expressiva e merece uma consideração especial (Tabela 3 e 4).

Tabela 3 - Relação dos 13 maiores fundos de pensão do Brasil - 2014

\begin{tabular}{l|l|r|r}
\hline & \multicolumn{1}{|c|}{ Fundos de Pensão } & Investimento $(\mathrm{R} \$)$ & Participantes ativos \\
\hline $1^{0}$ & PREVI & 174.073 .275 & 100.421 \\
\hline $2^{0}$ & PETROS & 68.883 .077 & 100.695 \\
\hline $3^{0}$ & FUNCEF & 57.168 .825 & 99.359 \\
\hline $4^{0}$ & FUNCESP & 22.845 .007 & 15.465 \\
\hline $5^{\circ}$ & FUNDAÇÃO ITAÚ UNIBANCO & 19.373 .152 & 25.283 \\
\hline
\end{tabular}


A ARISTOCRACIA OPERÁRIA E A PREVIDÊNCIA COMPLEMENTAR

\begin{tabular}{l|l|r|r}
\hline $6^{\circ}$ & VALIA & 17.762 .428 & 80.039 \\
\hline $7^{0}$ & SISTEL & 14.490 .571 & 1.925 \\
\hline $8^{\circ}$ & FORLUZ & 12.320 .497 & 8.652 \\
\hline $9^{\circ}$ & REAL GRANDEZA & 11.775 .494 & 4.374 \\
\hline 10 & BANESPREV & 11.739 .510 & 2.932 \\
\hline $11^{\circ}$ & FUNDAÇÃO ATLÂNTICO & 9.025 .473 & 14.720 \\
\hline $12^{\circ}$ & FAPES & 8.5999 .716 & 3.108 \\
\hline $13^{\circ}$ & POSTALIS & 7.969 .716 & 120.180 \\
\hline
\end{tabular}

Fonte: ASSOCIAC̄̃O BRASILEIRA DAS ENTIDADES FECHADAS DE PREVIDÊNCIA PRIVADA. Consolidado estatístico. São Paulo, 2015. Disponível em:<http://www.abrapp.org.br/Consolidados/ Consolidado\%20Estat\%C3\%ADstico_11_2015.pdf>. Acesso em: 5 abr. 2016.

Tabela 4 - Relação dos 13 maiores fundos de pensão do Brasil - 2015

\begin{tabular}{l|l|r|r}
\hline & Fundos de Pensão & Investimento (R\$) & \multicolumn{1}{|c}{ Participantes ativos } \\
\hline $1^{\circ}$ & PREVI & 164.910 .394 & 100.485 \\
\hline $2^{\circ}$ & PETROS & 65.655 .637 & 96.747 \\
\hline $3^{\circ}$ & FUNCEF & 57.499 .091 & 100.381 \\
\hline $4^{\circ}$ & FUNCESP & 23.248 .835 & 15.534 \\
\hline $5^{\circ}$ & FUNDAÇÃO ITAÚ UNIBANCO & 22.032 .289 & 39.397 \\
\hline $6^{\circ}$ & VALIA & 19.249 .009 & 80.200 \\
\hline $7^{0}$ & SISTEL & 15.564 .065 & 1.962 \\
\hline $8^{\circ}$ & FORLUZ & 13.275 .721 & 8.702 \\
\hline $9^{\circ}$ & BANESPREV & 12.806 .497 & 2.751 \\
\hline 10 & REAL GRANDEZA & 12.048 .127 & 4.249 \\
\hline $11^{\circ}$ & FUNDAÇÃO ATLÂNTICO & 9.4777 .161 & 13.905 \\
\hline $12^{\circ}$ & FAPES & 8.935 .782 & 3.103 \\
\hline $13^{\circ}$ & POSTALIS & $8.522,075$ & 117.057 \\
\hline
\end{tabular}

Fonte: (ASSOCIAÇÃO BRASILEIRA DAS ENTIDADES FECHADAS DE PREVIDÊNCIA PRIVADA, 2015).

Uma análise comparativa das tabelas acima apresentadas aponta que houve uma mudança de posição entre Banesprev e Real Grandeza. Esses fundos de pensão tiveram um aumento nominal nos valores recebidos, mas apresentaram queda no número de participantes ativos. Ver Tabela abaixo.

Tabela 5 - Aumento nominal dos fundos Banesprev e Real Grandeza

\begin{tabular}{l|l|l|l}
\hline & Fundos de Pensão & Investimento (R\$) & Participantes ativos \\
\hline $9^{\circ}$ & REAL GRANDEZA & 11.775 .494 & 4.374 \\
\hline $10^{\circ}$ & BANESPREV & 11.739 .510 & 2.932 \\
\hline
\end{tabular}




\begin{tabular}{l|l|l|l}
\hline $9^{\circ}$ & BANESPREV & 12.806 .497 & 2.751 \\
\hline $10^{\circ}$ & REAL GRANDEZA & 12.048 .127 & 4.249 \\
\hline
\end{tabular}

Fonte: (ASSOCIAÇÃO BRASILEIRA DAS ENTIDADES FECHADAS DE PREVIDÊNCIA PRIVADA, 2015).

A queda mais significativa foi observada nos dois principais fundos de pensão: Previ e Petros. A Previ teve uma queda de mais de 9 bilhões de reais, e a Petros uma queda de mais de 3 bilhões de reais, enquanto o Itaú Unibanco teve um crescimento de mais de 3 bilhões (Tabela 6).

Tabela 6 - Queda dos fundos dos dois principais fundos de pensão - Previ e Petros

\begin{tabular}{|l|l|r|r|}
\hline & Fundos de Pensão & Investimento (R\$) & \multicolumn{1}{|c|}{ Participantes ativos } \\
\hline $1^{\circ}$ & PREVI & 174.073 .275 & 100.421 \\
\hline $2^{\circ}$ & PETROS & 68.883 .077 & 100.695 \\
\hline $1^{\circ}$ & PREVI & 164.910 .394 & 100.485 \\
\hline $2^{\circ}$ & PETROS & 65.655 .637 & 96.747 \\
\hline
\end{tabular}

Fonte: (ASSOCIAÇÃO BRASILEIRA DAS ENTIDADES FECHADAS DE PREVIDÊNCIA PRIVADA, 2015).

\section{- A criação da Fundação de Previdência Complementar do}

\section{Servidor Público Federal (Funpresp)}

As contrarreformas da Previdência Social encetadas pelo Governo FHC (1998) e pelo Governo Lula (2003) encontraram seu coroamento no Governo Dilma, com a aprovação da Funpresp, que acabou com a aposentadoria integral dos servidores públicos e estabeleceu o teto do Instituto Nacional do Seguro Social (INSS) de dez salários mínimos para todos os servidores. Com isso se repassa para o setor privado o controle duma parte substancial da riqueza produzida pelos trabalhadores, de forma que a seguridade social deixa de constituir-se como direito, para assumir declarado caráter de investimento financeiro e mercadológico.

A criação do Funpresp, segundo Manzano (2012, p. 2), “[...] encaixa-se na lógica de avançar na financeirização capitalista e precariza ainda mais as condições de remuneração e vida dos trabalhadores do serviço público brasileiro." Os fundos de pensão servem como mecanismo de acumulação de riqueza pela mediação da expropriação dos trabalhadores; os recursos que deveriam servir para a aposentadoria são transferidos para a burguesia e a aristocracia sindical. Os prejuízos financeiros envolvendo os maiores fundos de pensão nos últimos anos demonstram o itinerário que deve percorrer 
a Funpresp, haja vista que os fundos não passam de instrumentos para alimentar a ciranda do capital financeiro e especulativo mediante a expropriação dos trabalhadores.

Como se não bastasse o conjunto de medidas aplicadas contra os trabalhadores pela mediação da privatização da Previdência Social, o governo Dilma acaba de encaminhar ao Congresso Projeto de Lei Complementar $n^{\circ}$ 257/2016, que trata do refinanciamento da dívida dos estados e do Distrito Federal através da supressão de mais de cinquenta direitos dos servidores públicos federais, estaduais e municipais. No seu artigo $4^{\circ}$, que trata do reajuste das contribuições previdenciárias e da constituição de novos fundos de pensão, afirma:

\begin{abstract}
I - instituição do regime de previdência complementar a que se referem os incisos 14, 15 e 16 do art. 40 da Constituição, caso ainda não tenha publicada outra lei com o mesmo efeito; III - elevação das alíquotas de contribuição previdenciária dos servidores e patronal ao regime próprio de previdência social para 14\% (quatorze por cento) e $28 \%$ (vinte e oito por cento) respectivamente, podendo ser implementada gradualmente em até 3 (três) anos [...] (BRASIL, 2016, p. 3).
\end{abstract}

O Governo Dilma Rousseff encaminha esse projeto ao Congresso no momento que precede a seu impeachment, o que denota que nem mesmo no instante em que precisava do apoio popular foi capaz de proporcionar qualquer concessão substancial à classe trabalhadora, mas continuou sendo um fiel defensor dos interesses do capital e da aristocracia sindical.

Os fundos de pensão alcançaram um status inimaginável nos governos petistas, o que fortaleceu a conexão entre sindicatos e empresas, sindicalistas e nova burguesia. Os fundos de pensão se revelam como uma forma exemplar da ascendência duma fração da classe trabalhadora à condição de administrador de empresas, financiador das atividades capitalistas, nova burguesia. Escreve Jardim (2010, p. 69):

[...] os sindicatos criam suas justificativas para investir em fundos de pensão; os fundos de pensão criam justificativas para investir em atividade produtiva; o governo cria suas justificativas para seus projetos de inclusão social, via mercado; e, por fim, as empresas criam justificativas para que se tornem credoras dos fundos de pensão.

A parceria entre os fundos de pensão e o governo fortaleceu a capacidade de convencimento do Governo Federal (Lula e Dilma) 
aos setores do empresariado que apresentavam resistências à forma petista de governar e que consideravam o governo do PT um governo de esquerda e uma ameaça ao poder do capital.

Nota-se um amálgama de interesses em que o capital se realiza através dos fundos de pensão, dos sindicatos, do governo e dos empresários; o ponto de partida de suas ações assenta-se na expropriação dos trabalhadores. Para isso reforça a afirmação dos preceitos da democracia, da cidadania, da inclusão social e da necessidade de redistribuição de renda. Esse discurso foi plenamente incorporado na agenda da CUT; todas as lutas dos trabalhadores são reduzidas à plataforma da necessidade de inclusão social e geração de emprego e renda, por meio de uma retórica que robustece a ideologia burguesa do empreendedorismo.

\section{CRISE DOS FUNDOS DE PENSÃO}

Enquanto principal avalista do governo petista, pela mediação da aristocracia operária, os fundos de pensão (Previ, Petros, Funcef etc.) passaram a investir os recursos tanto nas obras públicas, na perspectiva de gerar emprego, como nas obras do Programa de Aceleração do crescimento (PAC), em ações públicas voltadas para a classe trabalhadora (na mistificação das classes $\mathrm{C}, \mathrm{D}$ e E) ) $^{5}$, mediante o financiamento de programas como PMCMV e nos negócios relacionados à alimentação, ao consumo, ao varejo etc.

$\mathrm{O}$ investimento da poupança dos trabalhadores acionistas no setor produtivo é considerado como problemático pelos próprios representantes da burguesia, especialmente aquele que é direcionado ao setor imobiliário, bem como no financiamento das obras públicas de infraestrutura como hidroelétricas, aeroportos, estradas etc., pois o cenário de crise econômica torna a possibilidade de retorno dos investimentos realizados, incerta, e pode colocar em risco a aposentaria complementar de milhões de trabalhadores brasileiros. No entanto, os maiores perigos decorrem dos investimentos realizados no setor especulativo (bolsa de valores), na Vale (parceira da Samarco), na Petrobras (Sete Brasil), na Invepar (aeroporto de Guarulhos), nas empresas de Eike Batista etc.

Os prejuízos dos maiores fundos de pensão (Previ, Petros e Funcef) chegaram a R \$ 49,2 bilhões em 2015. No total, o prejuízo ultrapassou os R $\$ 120$ bilhões: os fundos estatais (mistos) representam $77 \%$ do rombo do setor e o privado fica com $27 \%$. Os prejuí- 
zos podem se intensificar devido à participação desses fundos nos projetos Sete Brasil (construção de sondas para Petrobras 6 ), Inepar (construção do aeroporto de Guarulhos em parceria com a OAS envolvida na Operação Lava Jato), Belo Monte (o Banco Nacional de Desenvolvimento Econômico e Social [BNDES] exige novas garantias para liberar recursos), Oi etc. A Petros contabiliza prejuízos nos diversos investimentos, inclusive na Lupatech (setor de petróleo) e no grupo Galileo. Na busca por lucros elevados, os fundos de pensão investiram desmedidamente em aplicações com elevada taxa de risco.

A Postalis acumulou um déficit de R \$ 5,7 bilhões entre 2012 2015. Os maiores prejuízos vieram das aplicações em papéis da dívida da Argentina e da Venezuela. As aplicações deficitárias foram feitas através do Bank of New York Mellon. Para cobrir os rombos da Postalis, os gestores do capital estão repassando o ônus para os trabalhadores, que terão de arcar com uma contribuição extra de R\$ 17,92 de seus soldos pelos próximos 26 anos.

Os gestores dos fundos de pensão buscam socializar com os trabalhadores tão somente os prejuízos, e nunca os lucros expressivos alcançados nos investimentos; estes lucros têm sempre uma finalidade privada e beneficiam exclusivamente os gestores, enquanto personificação do capital. Esses fundos tiveram nos últimos dez anos um crescimento entre $265,66 \%$ e $307,78 \%$ (MAIA, 2015), lucro que jamais chegou ao bolso dos trabalhadores acionistas.

A natureza empreendedora dos fundos de pensão pode ser observada no indiciamento de alguns de seus administradores, como, por exemplo, na figura do ex-presidente Alexej Predtechensky e no ex-diretor Florêncio da Costa, por gestão fraudulenta da Postalis, apropriação indébita no sistema financeiro e lavagem de dinheiro; além disso, a Polícia Federal solicitou a prisão do empresário Fabrizio Neves, pelos prejuízos causados aos trabalhadores que financiam a Postalis. O prejuízo dos fundos de pensão estende-se ao fundo de investimento do FGTS, haja vista que 30\% dos recursos do FI-FGTS foram aplicados nas empresas relacionadas aos escândalos da Lava Jato.

A prisão desses indivíduos revela a quintessência do modo petista de governar, da inusitada governança corporativa com responsabilidade social, da administração dos recursos públicos em consonância com os preceitos éticos. Realmente, a forma petista de 
assegurar a aposentadoria confortável dos trabalhadores pela mediação do sistema de capitalização revela seu desiderato fundamental: "[...] o surgimento de novos atores no mercado financeiro (sindicalistas, empresários éticos, trabalhadores acionistas, dirigentes de ONGs), o que acarreta, em certa medida, a recomposição das elites nacionais, especialmente no caso do Brasil.” (JARDIM, 2010, p. 17). Por promover a transformação da aristocracia operária numa nova burguesia é que se torna possível entender por que frações da burguesia nacional e internacional se ergueram contra o modo petista de governar e impulsionaram o movimento político que conduziu ao impeachment de Dilma Rousseff.

A aristocracia operária insere-se plenamente no processo de administração do capital e arrasta consigo a CUT, a CGT e a Força Sindical. Isso atenuou a luta de classes e flexibilizou a contraposição entre capital e trabalho. Através do desvelamento da natureza dos fundos de pensão e da participação da aristocracia operária na constituição dos fundos de pensão, pode-se chegar às motivações do arrefecimento do movimento sindical brasileiro nas últimas décadas e entender por que o lema da greve geral desapareceu da agenda do sindicalismo brasileiro. Através dos fundos de pensão afirmou-se a possibilidade de um ethos sindical distinto daquele forjado pelas lutas contra os patrões e as distintas representações do capital.

A análise dos fundos de pensão serve para demonstrar o caráter subserviente da burocracia operária brasileira nas últimas décadas e sua função motriz no processo de desmobilização da classe, em nome da constituição de uma agenda positiva consubstanciada na preservação dos postos de trabalhos e na difusão de uma ideologia fundada no empreendedorismo e na possibilidade de humanizar o capital. Pela mediação dos fundos de pensão, as greves operárias foram suplantadas pela possibilidade de capitalização e de transformação do trabalhador num empreendedor.

Através da administração dos fundos de pensão e da participação do gerenciamento do Estado burguês, a aristocracia operária plasmou a possibilidade de operar uma redistribuição de renda e inclusão social pela via do mercado, transformando frações da classe trabalhadora em agentes financeiros e em peças essenciais para subsidiar os projetos estatais de infraestrutura, energia etc.

Parece claro que a aristocracia sindical e operária constituiu a base fundamental de sustentação do modo petista de governar pela 
mediação dos fundos de pensão. Essa fração da classe trabalhadora acabou por se converter numa nova fração da burguesia; por isso a disputa parlamentar (impeachment de Dilma Rousseff) na atualidade consiste numa peça da disputa entre as frações da burguesia para assegurar o controle do Estado e o processo de expropriação da classe trabalhadora. Ao consolidar-se como gestora dos fundos de pensão, a aristocracia operária assumiu um discurso estereotipado de defesa dos trabalhadores, em que o mercado e a necessidade de capitalização dos recursos expropriados dos trabalhadores devem estar em plena consonância com os propósitos da expansão e acumulação do capital, num contexto histórico de crise profunda do sistema.

A crise econômica que arrasta a economia brasileira - reflexo da crise econômica mundial - coloca a necessidade de um novo rearranjo da distribuição da riqueza no Brasil. Isso significa que os bilhões concentrados nas mãos da aristocracia sindical devem passar para as mãos dos próprios agentes do sistema financeiro e empresarial alocados na Bolsa de Valores, Federação das Indústrias do Estado de São Paulo (Fiesp), Itaú, Bradesco e consortes.

O impeachment de Dilma Rousseff tem como foco tanto o controle das estatais quanto o controle dos fundos de pensão. A riqueza produzida pelos trabalhadores servirá para saciar temporariamente a fome de trabalho excedente do capital. Isso significa que os rombos e prejuízos anunciados dos fundos de pensão (Petros, Previ, Postalis etc.) devem se intensificar ainda mais. No entanto, os seus demiurgos serão os próprios capitalistas, e não mais setores advindos da aristocracia operária, como ocorreu na forma petista de governar.

\section{REFERÊNCIAS}

ARAÚJO, E. S. As reformas da previdência de FHC e Lula e o sistema brasileiro de proteção social. Revista Política Pública, São Luís, v. 13, n. 1, p. 31-41, jan./jun. 2009.

ASSOCIAÇÃO BRASILEIRA DAS ENTIDADES FECHADAS DE PREVIDÊNCIA PRIVADA. Consolidado estatístico. São Paulo, 2015. Disponível em:<http://www.abrapp.org.br/Consolidados/ Consolidado\%20Estat\%C3\%ADstico_11_2015.pdf $>$. Acesso em: 5 abr. 2016.

BRASIL. Projeto de Lei Complementar 257/2016. Estabelece o Plano de Auxílio aos Estados e ao Distrito Federal e medidas de estímulo ao reequilíbrio fiscal; altera a Lei no 9.496, de 11 de setembro de 
1997, a Medida Provisória no 2.192-70, de 24 de agosto de 2001, a Lei Complementar no 148, de 25 de novembro de 2014, e a Lei Complementar $\mathrm{n}^{\circ}$ 101, de 4 de maio de 2000; e dá outras providências. Brasília, DF, 2016. Disponível em:<http://www.camara.gov.br/ proposicoesWeb/prop_mostrarintegra;jsessionid=1C976D5BA56140F B3C168722E3F28104.proposicoesWeb1?codteor $=1445370 \&$ filename $=$ PLP+257/2016. Acesso em: 5 abr. 2016.

CAIXA DE PREVIDÊNCIA DOS FUNCIONÁRIOS DO BANCO DO BRASIL. Investimentos - Empresas participadas. Botafogo, 2015. Disponível em: $<$ http://www.previ.com.br/investimentos/empresasparticipadas $>$. Acesso em: 30 set. 2015.

CRUZ, D. A corrupção e os fundos de pensão. [S. 1.]: PSTU, 2005. Disponível em: $<$ http://www.pstu.org.br/node/5619>. Acesso em: 5 abr. 2016.

FUNDAÇÃO DOS ECONOMIÁRIOS FEDERAIS. Principais números. Brasília, DF, 2014. Disponível em: $<$ https://www.funcef.com. br/sobre-a-funcef/principais-numeros/>. Acesso em: 5 abr. 2016.

HOBSBAWM, E. Lenin e a "aristocracia operária". Acomuna, Lisboa, 2013. Disponível em:<http://acomuna.net/index.php/ contra-corrente/4542-lenine-e-a-aristocracia-operaria-por-eric-erichobsbawn>. Acesso em: 3 abr. 2016.

JARDIM, M. A. C. Fundos de pensão no Brasil: novo ethos sindical? In: COLÓQUIO INTERNACIONAL SABER E PODER, 10., 2008, Campinas. Anais eletrônicos... Campinas: Focus/Unicamp, 2008. Disponível em: $<$ https://www.fe.unicamp.br/focus/textos/JARDIM\%20 -20Fundos\%20de\%20pensao\%20no\%20Brasil.pdf $>$. Acesso em: 5 abr. 2016.

. Fundos de Pensão. Brasília, DF: Observatório de investimentos na Amazônia, 2010. Estudo 1. Disponível em:<http://www.inesc.org. br/biblioteca/textos/livros/obs-de-invest-da-amazonia_estudo-1>. Acesso em: 3 abr. 2016.

LESSA, S. Cadê o proletariado? São Paulo: Instituto Lukács, 2014.

MAIA, S. O saco sem fundo dos fundos de pensão: problemas de gestão e a crise econômica afetam o equilíbrio de algumas das principais fundações do país. Carta Capital, São Paulo, 2015. Economia. Disponível em:<http://www.cartacapital.com.br/ revista/845/saco-sem-fundo-5097.html>. Acesso em: 14 abr. 2016. 
MANZANO, S. Previdência Social e fundo de pensão: um debate necessário. Pravda.ru, Moscow, 2012. Disponível em: $<$ http://port. pravda.ru/busines/15-02-2012/32932-previdencia_pensoes-0/>. Acesso em: 3 abr. 2016.

OLIVEIRA, F. Crítica à razão dualista: o ornitorrinco. São Paulo: Boitempo, 2003.

SILVEIRA, G. $8^{\circ}$ Congresso Nacional da CUT: o fim de um ciclo de traição do sindicalismo amarelo. A Nova Democracia, Rio de Janeiro, ano 1, n. 11, jul. 2003. Disponível em: $<$ http://anovademocracia.com. br/no-11/1109-8o-congresso-nacional-da-cut-o-fim-de-um-ciclo-detraicao-do-sindicalismo-amarelo>. Acesso em: 4 abr. 2016.

TEIXEIRA, A. M. P. Previdência social no Brasil: da revolução passiva à contrarreforma. 2006. $252 \mathrm{f}$. Tese (Doutorado em Serviço Social) - Programa de Pós-Graduação em Serviço Social, Universidade Federal do Rio de Janeiro, Rio de Janeiro, 2006.

\section{NOTAS:}

1 A reforma encetada por FHC propiciou a primeira alteração substancial no processo de acesso à aposentadoria, ao estabelecer a distinção entre o processo de aposentaria por tempo de serviço e aposentadoria por tempo de contribuição. Além disso, estabeleceu teto para o valor dos benefícios, alterando os critérios de cálculos através da constituição do fator previdenciário, a criação do regime de previdência complementar e fim dos incentivos existentes aos servidores públicos que se aposentavam. A adoção do critério de tempo de contribuição acaba por discriminar os inúmeros trabalhadores lançados no mundo da informalidade e do desemprego. (ARAÚJO, 2009).

2 No prazo de oito meses (agosto de 2003), o governo Lula conseguiu aprovar a segunda reforma da previdência, extinguindo o direito dos servidores públicos à aposentadoria integral, a paridade entre os reajustes dos servidores ativos e inativos, e estabelecendo o teto para o valor dos benefícios aos servidores (novos ingressantes) equivalente ao do Regime Geral da Previdência Social (RGPS), a taxação dos servidores inativos e dos pensionistas etc. Assim, as aposentados passaram a ter seus salários reduzidos numa etapa da vida em que mais careciam de recursos financeiros para cuidar de sua saúde. (TEIXEIRA, 2006).

3 As Leis Complementares que tratam da previdência complementar estabeleceu as seguintes diretrizes e normatizações: “* criou a figura do 'instituidor' (sindicatos, associações profissionais, cooperativas etc.); * assegurou a participação dos trabalhadores nos órgãos deliberativos e diretivos; * introduziu a modalidade 'contribuição definida'; * inibiu desmandos administrativos mediante fortes penalidades aos dirigentes.” (JARDIM, 2010, p. 32, grifo do autor).

4 O ex-dirigente do Sindicato dos Bancários e da CUT, especialista em previdência privada, ficou conhecido pela atuação exemplar exercida como principal consultor de Fernando Henrique Cardoso para os projetos de privatização da Previdência Social. O velho quadro da aristocracia sindical tornou-se proprietário, em 2002, da empresa Gushiken \& Associados - que prestava assessoria aos fundos de pensão. O faturamento da referida 
empresa chegou a R \$1,5 milhão em 2003. Ao ascender à condição de ministro, Gushiken afastou-se do comando da empresa, que passou a se chamar Globalprev. A referida empresa alcançou um faturamento de R\$ 2 milhões em 2004 e de RS 969 mil em 2005 (CRUZ, 2005).

5 Segundo dados do Serasa, o número de inadimplentes no Brasil alcançou em 2015 a taxa de 56,4 milhões de pessoas, sendo 6,99 milhões com mais de 61 anos, o que representa $12,4 \%$ do total. Em 2013, 62,9\% da população ativa brasileira estava endividada. A denominada classe C perdeu seu fôlego nas compras em 2014, caindo para $26 \%$ sua participação, enquanto em 2007 era de $30 \%$. A população mais endividada é aquela que ganha entre 5 e 10 salários mínimos.

6 O prejuízo da Petrobras foi de $23 \%$ em 2015, ou seja, ela perdeu R $\$ 15$ bilhões. As ações da petroleira estão avaliadas em R $\$ 112,1$ bilhões neste ano, antes R $\$ 127$ bilhões no final de 2014. No auge, em maio de 2008, o conjunto de ações da Petrobras na Bolsa de Valores de São Paulo (Bovespa) somou R\$ 510,4 bilhões. As perdas resultantes da Operação Lava Jato chegam a 6,1 bilhões. 